large proportion of the daily calcium requirements, may well reduce the prevalence of bladder stones, ${ }^{7}$ but again, the effect of differing water hardness on the distribution of stones is completely unknown.

Development may result in endemic stones disappearing, but there is no evidence that the poor of the bladder stone belt in Asia have reached the stage of the declining disease experienced by the poor in England at the turn of the century.

General Practitioner,

Hurley Clinic,

London SE11 4HJ

1 Ellis H. A history of bladder stone. Oxford: Blackwell Scientific, 1969:1-25.

2 Spencer WG. Westminster Hospital: an outline of its history. London: Glaisher, 1924:3-29.

2 Spencer WG. Westminster Hospital: an outline of its history. London: Glas.

4 Thomas JMR. Vesical calculus in Norfolk. Br f Urol 1949;21:20-3.

5 Anderson DA. The nutritional significance of bladder stones. Br f Urol 1962;34:160-77.

6 Halstead SB. Cause of bladder stones in England: a retrospective epidemiological study. In: Smith LH, Robertson WG, Finlayson PB, eds. Urolithiasis. Clinical and basic research. London: Plenum, 1981:325-8.

7 Ashworth M, Hill SM. Endemic bladder stones in Nepal. Arch Dis Child 1988;63:1503-5.

8 Eckstein HB. Endemic urinary lithiasis in Turkish children. Arch Dis Child 1961;36:137-45.

9 Chutikorn C, Valyasevi A, Halstead SB. Studies of bladder stone disease in Thailand. 2. Hospital experience. Urolithiasis at Ubol Provincial Hospital, 1956-1962. Am f Clin Nutr 1967;20:1320-8.

10 Vermooten $\mathrm{V}$. The incidence and significance of the deposition of calcium plaques in the renat papilla as observed in the Caucasian and Negro (Bantu) population in South Africa. $\mathcal{F}$ Urol 1941;46:193-200.

11 Van Reen R. Idiopathic urinary bladder stones of childhood. Aust NZ F Surg 1980;50:18-22.

12 Sutor DJ, Wooley SE, Illingworth JJ. A geographical and historical survey of the composition of urinary stones. Br f Urol 1974;46:393-407.

13 Brockis JG, Bowyer RC, Ryan G, Taylor TA, Kamardi T, Rizal A. Endemic bladder stones in Indonesia. In: Smith LH, Robertson WG, Finlayson PB, eds. Urolithiasis. Clinical and basic Indonesia. In: Smith LH, Robertson W
research. London: Plenum, 1981:329-32.

14 Bowyer RC, Brockis JG, McCulloch RK. The role of common urinary constituents in the precipitation of ammonium acid urate. Clin Chem Acta 1979;99:221-7.

15 Fleisch $\mathrm{H}$, Bisaz $\mathrm{S}$. The inhibitory effect of pyrophosphate on calcium oxalate precipitation and its relation to urolithiasis. Experientia 1964;20:276.

16 Valyasevi A, Halstead SB, Dhanamitta S. Studies in bladder stone disease in Thailand. 6. Urinary studies in children, 2-10 years old, resident in a hypo- and hyperendemic area. Am $\mathcal{F}$ Clin Nutr $1967 ; 20: 1362-8$

\section{The new agenda for general practice computing}

\section{Time to exploit the potential for improving patient care}

In the past few years general practice computers have moved from innovation to implementation. The proportion of practices with computers has risen from a quarter in $1989^{1}$ to half this year, ${ }^{2}$ and within another two years $90 \%$ of practices will probably have them. This process has been accelerated by the new contract for general practice, with its requirements for screening and its reimbursement of some computer costs, ${ }^{3}$ and by the imminent arrival of indicative drug budgets, fund holding, and medical audit. ${ }^{4}$ Modern practice management demands computers.

This should not, however, be the end of the story. Most general practice computer systems still emphasise data entry and repetitive tasks rather than exploiting the full potential of the technology. Though they are adequate for entering and storing administrative data on patients and performing routine jobs, such as repeat prescribing and prevention recalls, ${ }^{2}$ they need to be developed to handle three key aspects: the computer clinical record, communications, and the quality of patient care.

Clinical recording is possible - just - with the more complex general practice computer systems, but there are many outstanding issues. The Read clinical classification is the only coding system to offer full cover for the symptoms, procedures, and events of primary care. ${ }^{5}$ Other classifications used in general practice computers may suffice for epidemi- ology and problem listing, but they fail as tools for recording everyday clinical care. The government's recent purchase of the rights to the Read clinical classification is therefore welcome because it removes the main obstacle to its general use.

Using the most appropriate classification system is not in itself enough. Techniques for entering clinical data need to be refined so that it takes no longer and is no more difficult than writing the paper record. Furthermore, the format of data entry and presentation needs to be flexible enough to allow the user to emphasise personal interests and incorporate new knowledge. If, for example, a new risk factor for coronary artery disease is identified, such as birth history, ${ }^{6}$ the doctor needs to be able to record it as such without recourse to user groups and programmers. It is not sufficient just to be able to record it; it should be recordable as a coronary risk factor and presented alongside the other coronary risks.

Every clinical entry will require an author and a date of entry, and overwritten data need to be retained in a background file. Such an "audit trail" is necessary for medicolegal purposes, especially if the computer record replaces the written one; for a doctor to interpret accurately clinical information; and for protecting the integrity of the medical record. It will increase in importance as record linkage allows the possibility of hospital doctors, nurse practitioners, and community nurses, as well as vocational trainees, contributing to the general practice database. With safeguards such as these, an accurate and well presented computer clinical record should improve the care of patients.

The second potential to be fully exploited is communication among computers. There are exciting prospects for links among general practice, hospitals, family health service authorities, pharmacists, and community services using fixed lines, modems, or smart cards. ${ }^{7}$ Such communications should ensure that all those concerned in a patient's care are kept fully informed and help in managing the internal market. ${ }^{4}$ In time patients may benefit more directly from computer access to general medical information and, as with banking, to simple services such as making appointments and ordering repeat prescriptions.

The last item on the immediate agenda is probably the most important: computer systems must begin to confront primary care's greatest challenge, the quality of patient care. ${ }^{7}$ At its most basic a computer based clinical support system can offer the doctor information and advice about a contemplated diagnosis, drug, or procedure. Such passive information may be augmented by advice relevant to the particular clinical case from a decision support system - either help with diagnosis or tailored advice on management plans. ${ }^{9}$

The most important development, however, is likely to be computer based protocols for clinical care. Each practice or practitioner will define the care they will offer to groups of patients. Such a protocol for patients with hypertension, for example, would include the diagnostic criteria, the targets for control, the frequency and content of review, and the therapeutic regimens to be used. Protocols can be designed for the common chronic and acute illnesses, prevention, and administrative aspects of care. ${ }^{10}$

Computer protocols will offer substantial benefits over conventional ones. Protocols can be compared with those of other practices and with a professional consensus, making differences between levels of proposed care explicit. This will lead to a greater degree of standardisation of care, and, as changes towards the middle ground will be voluntary, will do so without interfering with clinical freedom.

When a patient for whom a protocol is appropriate consults the doctor the computer will offer the chance to enter data using that protocol. As well as prompting the doctor to live up 
to his or her own expectations, this will allow continuous accurate medical audit. The definition of computer protocols for care and the feedback of comparisons between the protocols and the realities achieved offer the best opportunity available for improving the consistency and quality of patient care in general practice.

This then is the agenda for the next phase for computers in general practice-clinical recording, communication, and computer aided medical audit, all aimed at enhancing the quality of patient care. The technology exists now. It requires only that the medical profession and the suppliers of general practice computer systems should work together to make it happen.

MIKE PRINGLE

Senior Lecturer,

Department of General Practice,

Nottingham University Medical School,

Nottingham NH7 2UH

1 Statistics and Management Information Division, Department of Health. Computing survey 1989 London: Department of Health, 1989.

Statistics and Management Information Division, Department of Health. Computing survey 1990 London: Department of Health, 1990.

3 Secretaries of State for Health and Wales. The 1990 contract for general practice. London: Department of Health, 1989.

4 Secretaries of State for Health, Wales, Scotland and Northern Ireland. Working for patients. London: HMSO, 1989

London: HMSO, 1989
Chisholm J. The Read clinical classification. BMf 1990;300:1092.

6 Barker DJP, Bull AR, Osmond C, Simmonds SJ. Fetal and placental size and risk of hypertension Barker DJP, Bull AR, Osmond C, Sim
in adult life. BMf 1990;301:259-62.

7 Walsworth-Bell J, Horsley SD. The use of smart cards in the NHS. Health Trends 1988;20:86-8.

8 Royal College of General Practitioners. Quality in general practice. London: Royal College of General Practitioners, 1985

9 Davies M, Owen K. Complex uncertain decisions: medical diagnosis. London: HMSO, 1990.

10 Chan DH, Chan N-F, Chan C, Lui G, Donnon SPB. Implementation of a microcomputer-based opportunistic health maintenance programme in a general practice teaching clinic. $f(R$ Coll $G e n$ Pract 1988;30:360-2.

\section{Selling the pathology service}

\section{Based on an incomplete understanding of what it does}

Last month the Department of Health issued two small booklets that illustrate a profound ignorance of the way that parts of the NHS work and contain within them suggestions that, if adopted, would soon open the way to a two tier health service

The booklets are Pathology Guide and its accompanying Pathology Workbook, produced by the department's income generation unit and issued by the NHS Management Executive, and they outline ways in which managers can generate extra income from pathology (and radiology) services. In launching the scheme, Stephen Dorrell, Parliamentary Secretary for Health, cited a potential market of $£ 100 \mathrm{~m}$ : "All that is needed to get this money working for us is a pathology service which is efficient and used to its full capacity." The booklets were produced without consultation with pathologists' professional bodies, and, although the booklets are entitled "pathology" they also include radiological services. I doubt whether the radiologists were consulted either.

The documents represent poorly thought out management concepts on the marketing of services crudely applied to pathology laboratories and radiology departments. Laboratories (and radiology departments) fulfil a far wider role than simply providing a "results" service, but there is no hint here of the consultative role provided to both the hospital and general practitioner services; of the importance of the service in the training of medical and non-medical staff; and of the way in which high standards of teaching and research are maintained. The philosophy summarised in these documents is of a supermarket style diagnostic service.

Moreover, I do not believe that "spare capacity exists in most laboratories." Many consultant pathologists still work single handed with a workload far above the recommendations of the Royal College of Pathologists and are faced with an ever increasing workload from the outcome of the white paper-population screening, management, and medical audit. Undoubtedly there are departments that could take on additional analytical work, but this will usually be at the expense of teaching, research, and development. The emphasis on throughput will inevitably result in a conflict with quality as individuals may try to solve problems on the periphery of their experience and in some cases outside it. Emphasis on throughput will particularly affect pathology subspecialties that cannot generate additional numbers through population screening programmes and the like. If financial incentives are offered for this additional work this will also have a serious effect on recruitment into specialised areas that cannot generate it.

All professional groups will need to assess carefully how these incentives are presented by managers. Even now many employees in the NHS have to undertake non-NHS work without personal gain, and it may not be long before undertaking this additional work will become part of local contracts. Staff undertaking this additional work may also have little say in how the profits are used. There is always a delay, often long, between undertaking or developing excessive workload and showing a manager that this has happened and that it is having a deleterious effect on other aspects of the service. That is why nationally agreed and accurate performance indicators are so important.

The most worrying aspect of these proposals, however, is their implications for the future of the health service. The Pathology Guide claims that providing some services will need extra resources - for example, separate receptionists, separate waiting areas, and a system for rapid interpretation of results for private patients. This undermines the principle that the NHS should be equally available to all and will probably be distasteful to most NHS staff. The only criterion for access to facilities should relate to the urgency of clinical need; the same principle should apply to the distribution of results.

The guide rightly emphasises the quality of the service that the NHS can offer as a competitor and that the key factor in determining price will be value. Value should be beyond question, and with the increasing commitment of the royal colleges to medical audit, external quality assessment schemes, and accreditation of laboratories that value will continue to increase. Sadly, its biggest threat is excessive pressure for increased throughput without a proper understanding of the broader responsibilities of a pathology and radiology service.

Consultant Neuropathologist,

Royal Hallamshire Hospital,

Sheffield S10 2JF

\section{Correction}

Hypercalcaemia in malignancy

A printer's error occurred in this editorial by Dr D A Heath $(1989 ; 298: 1468)$. The dosage of disodium etridonate should be $7.5 \mathrm{mg} / \mathrm{kg} /$ day and not $7.5 \mathrm{mg} / \mathrm{g} / \mathrm{day}$ as printed. 